\title{
Efficacy and safety of travoprost alone or in combination with other agents for glaucoma and ocular hypertension: patient considerations
}

This article was published in the following Dove Press journal:

Clinical Ophthalmology

5 October 2010

Number of times this article has been viewed

\author{
Emilio Rintaro Suzuki Jr \\ Cibele Lima Belico Suzuki \\ Instituto de Olhos Pampulha, Belo \\ Horizonte, Minas Gerais, Brazil
}

\begin{abstract}
Travoprost is a prostaglandin analog used in the management of glaucoma and ocular hypertension for reducing intraocular pressure (IOP). The IOP-lowering efficacy of travoprost has been shown to be similar to that of other prostaglandins, including latanoprost and bimatoprost. When compared with fixed combinations of timolol and either latanoprost or dorzolamide, travoprost alone can reduce mean IOP in a similar or superior manner. Concomitant therapy of travoprost and timolol can reach even greater IOP reductions than fixed combinations at some time points, but with no difference in the early morning, when IOP is usually higher. In addition, the long duration of action of travoprost can also provide better control of IOP fluctuation, probably due to its stronger prostaglandin $\mathrm{F}$ receptor mechanism. The side effects of travoprost do not represent a risk to the vision or health of the patient. The proven efficacy and safety combined with convenient once-daily dosing for travoprost increases patient compliance with treatment for glaucoma.
\end{abstract}

Keywords: travoprost, prostaglandin, glaucoma

\section{Introduction}

Glaucoma is an optic neuropathy usually associated with increased intraocular pressure (IOP) that causes progressive visual field loss. This disease is one of the main causes of blindness worldwide. ${ }^{1}$ Although several risk factors are associated with glaucoma onset and progression, the presence of high levels of IOP is the most important risk factor and the only one that can be changed. ${ }^{2}$ Reduction of IOP is the most efficient and clinically accepted therapy to avoid deterioration of optic disc and progression of visual loss. ${ }^{3}$

Fortunately, topical medications for lowering IOP have shown good efficacy and safety in glaucoma and ocular hypertension patients. ${ }^{4}$ There are five categories of topically administered medications available for the treatment of glaucoma, ie, cholinergic agents, adrenergic agonists, carbonic anhydrase inhibitors, $\beta$-adrenoceptor antagonists, and prostaglandin analogs (PGAs). ${ }^{6,7}$ PGAs and $\beta$-adrenoceptor antagonists are the most frequently used topical medications for reducing IOP in patients with glaucoma. ${ }^{8}$ Moreover, PGAs are the most effective drugs to reduce IOP, with fewer systemic side effects, and requiring only a single drop daily. Currently, the PGAs have been found to be more effective than $\beta$-blockers in the reduction of IOP in patients with glaucoma and ocular hypertension. ${ }^{9,10}$

Travoprost acid, the biologically active form of travoprost, is a prostaglandin $\mathrm{F}_{2 \mathrm{a}}$ analog and a fully selective agonist to the prostaglandin F receptor. ${ }^{11-14}$ This receptor is abundant in the longitudinal ciliary muscle and iris sphincter of the human eye. ${ }^{11,13}$ 
PGAs reduce IOP by increasing the outflow of aqueous humor through the uveoscleral pathway. ${ }^{15,16}$

However, if treatment with monotherapy fails to reduce or maintain IOP under control, a fixed combination can be an alternative to keep daily single-drop therapy. ${ }^{4}$ Combining drugs that have different modes of action should provide an additional IOP lowering effect. ${ }^{11,16}$

It is known that inadequate compliance with glaucoma therapy is a risk factor for progression of the disease and blindness. Several guidelines indicate that adequate glaucoma therapy requires a high level of compliance and this can be better achieved with lower frequency of use of ocular medications. ${ }^{7}$ The Ocular Hypertension Treatment study found that, after five years of therapy, about $40 \%$ of patients required two or more medications to control IOP from baseline of $20 \%$ and a final IOP of $<24 \mathrm{mmHg}$. A number of studies have found poor compliance in more than one-third of patients with glaucoma (depending on the therapy used), ${ }^{2}$ and compliance is further compromised by increasing age. ${ }^{4}$

Rossi et al used an electronic device, ie, the Travatan Dosing Aid, in a six-month cohort study to assess adherence in glaucoma patients under travoprost or travoprost-timolol therapy. Even with single-drop therapy, only $30.3 \%$ of patients had perfect adherence. The major causes of noncompliance were advancing age and duration of therapy. ${ }^{5}$

In this scenario, a fixed combination administered once daily may offer better and more convenient treatment for patients with glaucoma or ocular hypertension than the concomitant administration of two medications. ${ }^{4,16}$

Usually, medical therapy is the first-choice procedure to treat primary open-angle glaucoma and some patients with ocular hypertension. ${ }^{17}$ However, when medical therapy with topical agents fails to lower IOP, laser and more invasive surgical procedures are needed to reduce the risk of progressive visual field loss in patients with initial or advanced primary open-angle glaucoma and the development of a defect in patients with ocular hypertension. ${ }^{2,3,18}$

\section{Efficacy}

Travoprost has been compared with several drugs, especially timolol and fixed combinations of timolol. This kind of comparison has an important clinical impact because of the widespread use of timolol and timolol fixed combinations worldwide.

Goldberg et al randomized 573 patients with openangle glaucoma or ocular hypertension to treatment with two different concentrations of travoprost, ie, $0.0015 \%$ and $0.004 \%$ once daily or to treatment with timolol maleate $0.5 \%$. The enrolled subjects had untreated IOP of at least $24 \mathrm{mmHg}$, with a mean IOP among all subjects of approximately $26 \mathrm{mmHg}$. After nine months of treatment, mean IOP averaged across six study visits was lower with travoprost $0.004 \%$ than with timolol $0.5 \%$ at all time points. Mean IOP reductions ranged from 8.0 to $8.9 \mathrm{mmHg}$ with travoprost $0.004 \%$ versus 6.3 to $\mathrm{mmHg}$ with timolol $0.5 \% .^{10}$

Figueiredo et al compared IOP reduction and the effect on ocular blood flow between travoprost, latanoprost, bimatoprost, and unoprostone in 92 patients with open-angle glaucoma or ocular hypertension without previous treatment. After three months, travoprost and bimatoprost showed a similar $7.2 \mathrm{mmHg}$ IOP reduction, whereas latanoprost and unoprostone showed $6.9 \mathrm{mmHg}$ and $1.6 \mathrm{mmHg}$ reductions, respectively. It was shown that travoprost could also increase pulsatile ocular blood flow. ${ }^{19}$

Parrish et al compared three PGAs head-to-head in a randomized, 12-week prospective trial including 410 subjects. This group reported no differences in mean IOP reduction between travoprost $(8.0 \mathrm{mmHg})$, latanoprost $(8.7 \mathrm{mmHg})$, and bimatoprost $(8.6 \mathrm{mmHg}, P=0.128) .{ }^{20}$

In another study, Cantor et al compared the efficiency of travoprost and bimatoprost treatment in 157 patients over six months at different time points. The mean IOP reductions with travoprost and bimatoprost were, respectively, 5.7 versus $7.1 \mathrm{mmHg}$ at $9 \mathrm{am}(P=0.014), 5.2$ versus $5.9 \mathrm{mmHg}$ at $1 \mathrm{pm}$ $(P=0.213)$, and 4.5 versus $5.3 \mathrm{mmHg}$ at $4 \mathrm{pm}(P=0.207)$. IOP reductions $\geq 20 \%$ and $\geq 30 \%$ were achieved by statistically similar proportions of patients as revealed by responder analysis, and both groups presented statistically equivalent investigator-determined clinical success which was based on drug tolerability and achievement of target IOP. ${ }^{21}$

Franks et al studied the IOP-lowering response of patients with open-angle glaucoma or ocular hypertension treated with travoprost and a fixed combination of latanoprost $0.005 \%$ and timolol $0.5 \%$. In this study, 110 subjects were randomized to receive either travoprost once daily in the evening or latanoprosttimolol once daily in the morning and, depending on randomization, masking was achieved by use of a placebo in the morning. IOP reduction between the two groups showed no statistically significant difference at any time point in the study. Travoprost lowered IOP by $7.0 \mathrm{mmHg}$ and latanoprost-timolol by $6.4 \mathrm{mmHg}$ in the morning and, at the end of the day, IOP reductions were 6.8 and $6.1 \mathrm{mmHg}$, respectively. ${ }^{11}$

Suzuki Jr et al compared travoprost and the fixed combination of dorzolamide $2 \%$ and timolol $0.5 \%$ on relative IOP reduction. In a study that was masked to investigators but not to subjects, 56 patients with open-angle glaucoma or ocular hypertension were randomized to receive either 
travoprost once daily in the evening or dorzolamide-timolol twice daily. A statistically significant lower mean IOP was observed with travoprost than with dorzolamide-timolol $(P<0.01)$ across all visits and time points. The mean IOP with travoprost ranged from 7.1 to $7.5 \mathrm{mmHg}$, compared with 4.5 to $4.8 \mathrm{mmHg}$ with dorzolamide-timolol at three and six weeks. In addition, more complaints were reported by patients in the dorzolamide-timolol group. ${ }^{22}$

In conclusion, the most relevant studies comparing travoprost with other drugs showed similar IOP reductions with travoprost and with latanoprost or bimatoprost. Moreover, travoprost showed similar or superior results when compared with fixed combinations of timolol with either latanoprost or dorzolamide.

\section{Effect on IOP fluctuation}

Because circadian IOP variability has emerged as an independent risk factor for the progression of glaucoma, the circadian IOP-lowering profiles of medications have become a relevant measure of their clinical efficacy. ${ }^{23,24}$ Considering this, the endurance of travoprost's IOP effect periods ranging from 24 to 84 hours postdose have been evaluated by several studies. ${ }^{16,17}$

Orzalesi et al compared the 24-hour IOP-lowering profiles of travoprost, latanoprost, and bimatoprost in a crossover study. Sequential treatment with each of the three drugs for one month (with a one-month washout between each treatment) was given to 44 subjects with primary open-angle glaucoma or ocular hypertension. The patients had 24-hour IOP assessments at baseline and at the end of each month-long treatment session. The mean circadian IOP (measured in the sitting position using Goldmann applanation tonometry) between the three drugs showed no statistically significant difference. Mean circadian IOP reduction of travoprost was $7.1 \mathrm{mmHg}$, compared with $6.7 \mathrm{mmHg}$ for latanoprost and $7.9 \mathrm{mmHg}$ for bimatoprost $(P=0.08)$. Knowing that supine IOP is generally higher than sitting IOP, another relevant aspect of a drug`s IOP-lowering profile is the ability to lower IOP in the supine position, ie, while asleep at night). In order to measure supine IOP they also used an electronic tonometer, and no differences in circadian IOP reduction between the three drugs were observed. ${ }^{25}$

Garcia-Feijoo et al undertook a prospective, randomized, double-masked trial to compare the duration of action of travoprost and latanoprost in 62 patients with primary open-angle glaucoma or ocular hypertension. During 14 days, the patients received once-daily treatment at $8 \mathrm{pm}$, and then sitting and supine IOP assessments using Perkins tonometry were made every four hours out to 48 hours after drug administration. In the first and second 24-hour periods after the last dose, the mean IOPs produced by travoprost in the sitting position were lower than for latanoprost, but this was not statistically significant. On the other hand, IOP was significantly lower in the travoprost group at every IOP measurement for $12,16,20,24,36,40$, and 48 hours after the last dose in the supine position. Mean travoprost IOPs from the periods 0-24, 24-48, and 0-48 hours postdosing were lower than for latanoprost in the supine position $(P<0.05) .{ }^{26}$

Taking these studies together, it becomes clear that the duration of action of travoprost exceeds its 24-hour dosing period, and that reductions from baseline are seen up to 63 hours after the last dose. At the end of each dosing period, travoprost, which is labeled for dosing once daily in the evening, has been shown to provide better IOP control when compared with latanoprost. ${ }^{16,25,26}$

\section{When a stronger dose is needed for glaucoma control}

Almost one half of glaucoma patients on topical treatment require more than one drug to control IOP, and patient compliance with glaucoma treatment is clearly affected when multiple drops are needed. Fixed combinations can be an alternative to maintain adequate IOP control and improve compliance. ${ }^{16,22}$ Schuman et al in a prospective, randomized, double-masked, multicenter trial compared a fixed combination once daily in the morning with concomitant therapy using travoprost once daily in the evening and timolol twice daily in 403 subjects with open-angle glaucoma or ocular hypertension during three months. The results showed that at every visit and time point, the IOP-lowering from baseline was greater with the fixed combination than with timolol monotherapy. On the other hand, significantly better IOP reduction from baseline at two of nine time points was observed with concomitant dosing of the separate components, while equivalent reductions were observed at the remaining seven time points. IOP reductions for the fixed combination, travoprost and timolol concomitant therapy, and timolol from baseline measured across the visits and time points were $6.8-8.6 \mathrm{mmHg}, 7.3-8.4 \mathrm{mmHg}$ and 4.6-7.0 $\mathrm{mmHg}$, respectively. ${ }^{27}$

In another prospective, randomized, multicenter, doublemasked trial, Hughes et al also compared the fixed combination dose once daily in the morning with the concomitant administration of travoprost once daily in the evening and timolol once daily in the morning in 316 subjects with open-angle glaucoma or ocular hypertension over three months. They found that at most time points the fixed combination was 
not inferior to concomitant dosing, inasmuch as at seven of nine time points, the upper $95 \%$ confidence limit for the difference in mean IOP between the two treatment groups was within $\pm 1.5 \mathrm{mmHg}$. The two time points that were an exception to this both occurred in the morning and on separate visits. The fixed-combination IOP reductions from baseline were 7.4-9.4 $\mathrm{mmHg}$ and for travoprost and timolol concomitant therapy were $8.4-9.4 \mathrm{mmHg} .^{28}$

It can be concluded from these studies that there is better efficiency with concomitant therapy rather than with the combination at several time points. The different dosing protocols, in which the prostaglandin is given in the morning in the fixed combination group and in the evening in the concomitant group, might influence this finding because evening dosing of prostaglandins rather than morning dosing is generally recommended. Therefore, the occasional transient conjunctival hyperemia that follows topical dosing tends to have lesser clinical significance. In contrast, because of the natural reduction of aqueous humor production at night, beta-blockers are more effective for lowering IOP with morning dosing rather than with evening dosing. Therefore, the fixed combination with timolol could have better performance as a result of the morning dosing. ${ }^{16,29,30}$

In order to understand better the efficacy of the travoprost-timolol fixed combination when dosed in the morning versus evening, Denis et al evaluated 92 subjects with open-angle glaucoma or ocular hypertension in a prospective, randomized, double-masked trial. The fixed combination either in the morning or in the evening was given to patients for six weeks. The results were similar in the morning group and in the evening group, and their IOP reductions ranged from 16.5 to $16.7 \mathrm{mmHg}$ and from 16.1 to $17.2 \mathrm{mmHg}$, respectively. The $8-10 \mathrm{mmHg}(32 \%-38 \%)$ IOP reductions from baseline of were statistically significant and clinically relevant in both groups. ${ }^{31}$

Pfeiffer et al assessed the safety and efficacy of changing to the travoprost-timolol fixed combination from other monotherapies or adjunctive therapies in 472 patients with uncontrolled or below-target glaucoma therapy. After three months, the travoprost-timolol fixed combination reduced IOP from the level prior to treatment by $5.6( \pm 2.6) \mathrm{mmHg}$. Ocular hyperemia was the most frequent adverse effect ( $n=21,4 \%$ ). Both patients and physicians preferred the travoprost-timolol fixed combination compared with all prior and common individual treatments. ${ }^{32}$

\section{Adding other drugs to travoprost}

The effects of adding topical carbonic anhydrase inhibitors or topical alpha-agonists to PGAs remains little explored. ${ }^{33}$
It has been shown that dorzolamide is more effective than timolol or brimonidine $0.2 \%$ as adjunctive therapy for lowering IOP in eyes already on latanoprost. ${ }^{34}$

In another double-masked crossover trial, Konstas et al could not find any difference in 24-hour IOP measurements between adjunctive dorzolamide twice daily and brimonidine $0.15 \%$ twice daily in combination with latanoprost after six weeks of adjunctive therapy.

The mean baseline IOP of the 79 patients was 22.5 (15-31) mmHg. Four weeks later, the mean IOP of the 78 patients under treatment with a combination of travoprost and brinzolamide was 18.5 (12-24) mmHg. Finally, 12 weeks later, the mean IOP for 71 evaluable patients was 18.2 (10-27) $\mathrm{mmHg}$. At all time points, IOP was significantly reduced when compared with baseline values $(P<0.0001)$. The average IOP had decreased by $3.9 \mathrm{mmHg}$ (17.4\%) after four $(\mathrm{n}=78)$ and by $4.2 \mathrm{mmHg}(18.4 \%)$ after $12(\mathrm{n}=71)$ weeks of combined travoprost and brinzolamide therapy when compared with the monotherapy baseline of travoprost ophthalmic solution $0.004 \%$. After four weeks of adjunctive treatment, $56 \%$ of patients $(n=78)$ and $63 \%$ of patients after 12 weeks $(n=71)$ had at least an additional $15 \%$ reduction in $\mathrm{IOP}^{35}$

Reis et al randomized 52 eyes with open-angle glaucoma or ocular hypertension to receive adjunctive therapy of timolol $0.5 \%$, brinzolamide $1 \%$, or brimonidine tartrate $0.2 \%$ in conjunction with travoprost. Brinzolamide $1 \%$ and timolol maleate $0.5 \%$ showed greater IOP reduction compared with brimonidine $0.2 \% .^{36}$

The advantages of simpler dosing for topical glaucoma therapy can be better noticed in a regular daily-life environment than in clinical studies. This might be due to the fact that single-drop therapy is simple and flexible for patients, as well as the absence of the washout effect present with multiple-drop therapies. Moreover, maintenance of shortand long-term adherence to glaucoma medication regimens is better with a once-daily travoprost-timolol combination rather than with multiple-drop therapy.

As reported by Covert et al, 30.2\% of patients treated with latanoprost $0.005 \%$ and $23.2 \%$ treated with bimatoprost $0.03 \%$ required adjunctive treatment. Travoprost accounted for $22.5 \%$ of the adjunctive therapy. ${ }^{37}$ Netland et al reported that only $8 \%$ of patients treated with travoprost $0.004 \%$ needed adjunctive treatment. ${ }^{9}$

\section{Safety of prostaglandin analogs}

In studies to evaluate the relative incidence of hyperemia between prostaglandins, Netland et al found that the 
incidence of hyperemia caused by latanoprost was $27.6 \%$, while travoprost had a rate of $49.5 \%$, and Cantor et al observed hyperemia in $21.1 \%$ of eyes treated with bimatoprost and in $14.8 \%$ in eyes treated with travoprost. ${ }^{9,21}$ The use of travoprost $0.004 \%$ induced a conjunctival hyperemia incidence of $32.5 \%-49.5 \%$, whereas timolol maleate $0.5 \%$ treatment had an incidence of $7 \%-14 \% .^{16}$

Hyperemia is usually mild and unlikely to interrupt clinical studies. In fact, improvement of hyperemia during continued dosing has been reported. ${ }^{10}$

Parrish et al found a higher incidence of hyperemia for bimatoprost, ie, 68.6\%. Travoprost and latanoprost had a hyperemia incidence of $58 \%$ and $47.1 \%$, respectively. ${ }^{20}$

It must be taken in consideration that the use of different methods for evaluation of hyperemia might be the cause of the significant variation of reported rates for conjunctival hyperemia, even for individual drugs. These methods have included patient complaints, tiered scoring systems used for subjective investigator grading of hyperemia, as well as photographic evaluation. Apart from the aesthetic adverse effects, conjunctival hyperemia has not been reported to be a major vision or health problem.

PGAs can also induce darkening of the iris, and its incidence in the literature varies according to the different methods used in its evaluation. Netland et al reported that iris hyperpigmentation was observed in $5.2 \%$ of eyes treated with latanoprost and in $3.1 \%$ in eyes treated with travoprost. Another study by Cantor et al in 157 subjects compared the effects of travoprost and bimatoprost, and iris hyperpigmentation developed in a single bimatoprost-treated eye., ${ }^{9,21}$ Because of the fact that green and mixed hazel eyes are most affected by iris hyperpigmentation, the baseline eye color might influence the risk of developing this adverse effect. It was shown in a five-year study by Alm et al that over $75 \%$ of green-brown or yellow-brown eyes suffered iris hyperpigmentation after latanoprost treatment, while brown or blue/grey eyes were not affected. ${ }^{38}$ Overall, the incidence of iris hyperpigmentation caused by one year of daily treatment with travoprost $0.004 \%$ is low (less than 5\%), and is considered to be a cosmetic issue rather than a harmful adverse effect with regard to either vision or health. ${ }^{16,38}$

The eyelashes can suffer some changes during treatment with travoprost and other PGAs. These drugs can induce eyelashes to increase in number and can cause alteration in their length, thickness, and darkness. ${ }^{16}$

A new preservative for travoprost, SofZia ${ }^{\mathrm{TM}}$ (Alcon Laboratories, Fort Worth, TX, USA), seems to offer better tolerability than benzalkonium chloride (BAK) for patients with ocular surface complaints. BAK-free travoprost was compared with latanoprost containing BAK preservative in patients with superficial punctate keratopathy. After replacing latanoprost containing BAK with travoprost containing SofZia, the score for superficial punctate keratopathy decreased significantly three months later. ${ }^{39,40}$

The integrity of the blood-aqueous barrier after prostaglandin treatment has been evaluated by Cellini et al. Cell and flare values of the anterior chamber were measured in 60 glaucoma patients who were randomly assigned to receive travoprost, latanoprost, or bimatoprost. A flare meter was used to quantify both cell and flare at baseline and after three and six months of therapy. The results showed significant increases in cell and flare from baseline at three and six months, and slight diminution of cell flare between three and six months of therapy for all three drugs, whereas significantly more cell and flare were induced by latanoprost at three and six months. After three months of therapy, travoprost induced more cell and flare than bimatoprost, and no significant difference between these two drugs was observed at six months. ${ }^{41}$

Similarly, in a crossover design, Arcieri et al studied the effect of these drugs in 34 phakic individuals. The patients received travoprost, latanoprost, and bimatoprost for four weeks, with a four-week washout between each drug. The drugs did not increase anterior chamber flare, nor did they induce differences in flare levels in a drug-dependent manner. ${ }^{42}$

The use of all three PGAs has been associated with macular edema, even though other risk factors for macular edema were already present, and usually prior to both complicated and uncomplicated cataract surgery. Macular edema resolved, and visual acuity returned to baseline after drug discontinuation. Macular edema is a rare outcome of travoprost or other PGA treatment. Its incidence is higher in pseudophakic eyes, and in eyes with other risk factors for macular edema, while probably no risk of macular edema can be implicated in phakic eyes without risk factors. Macular edema, as well as impaired visual acuity, can be resolved with interruption of PGA treatment. ${ }^{43-46}$ Notably, the cardiovascular and pulmonary systems, and blood and urine are not considerably affected by travoprost treatment. ${ }^{16}$

\section{Conclusion}

IOP reduction is efficiently achieved by the PGAs. Among them, travoprost can lower IOP levels to $6.5-9.0 \mathrm{mmHg}$, being as effective as products combining timolol with latanoprost or dorzolamide. Other benefits of travoprost include probable increased efficacy in black patients, eyes with pseudoexfoliation, eyes with chronic angle-closure 
glaucoma, and following cataract surgery. Even though the recommended dosing is once daily, travoprost can lower IOP up to 63 hours after the last dose, demonstrating greater IOP control at the end of each dose compared with latanoprost. Despite the development of minor adverse effects, such as conjunctival hyperemia, iris and eyelid hyperpigmentation, eyelash changes, and other rare cases of iritis and macular edema, which are common to PGA therapy, the efficiency and safety of travoprost have been extensively demonstrated. Moreover, convenient once-daily dosing has made travoprost a first-line therapy for glaucoma treatment and, in fixed combination with timolol, an option to enhance IOP control when monotherapy fails.

\section{Disclosure}

The authors report no conflicts of interest in this work.

\section{References}

1. Resnikoff S, Pascolini D, Etya'ale D, et al. Global data on visual impairment in the year 2002. Bull World Health Organ. 2004;82(11):844-851.

2. The AGIS Investigators. The advanced glaucoma intervention study (AGIS) 7. The relationship between control of intraocular pressure and visual field deterioration. Am J Ophthalmol. 2000;130(4):429-440.

3. Heijl A, Leske MC, Bengtsson B, et al. Early Manifest Glaucoma Trial Group. Reduction of IOP and glaucoma progression results from the Early Manifest Glaucoma Trial. Arch Ophthalmol. 2002;120(10):1268-1279.

4. Hoy SM, Keam SJ, Keating GM. Travoprost/timolol. Drugs Aging. 2006;23(7):587-597.

5. Rossi GC, Pasinetti GM, Scudeller L, Tinelli C, Milano G, Bianchi PE. Monitoring adherence rates in glaucoma patients using the Travatan Dosing Aid. A 6-month study comparing patients on travoprost $0.004 \%$ and patients on travoprost $0.004 \% /$ timolol $0.5 \%$ fixed combination. Expert Opin Pharmacother. 2010;11(4):499-504.

6. Marquis RE, Whitson JT. Management of glaucoma: Focus on pharmacological therapy. Drugs Aging. 2005;22(1):1-21.

7. Camras CB, Toris CB, Tamesis RR. Efficacy and adverse effects of medications used in the treatment of glaucoma. Drugs Aging. 1999;15(5):377-388.

8. American Academy of Ophthalmology. Primary Open-Angle Glaucoma Suspect, Preferred Practice Pattern. San Francisco, CA: American Academy of Ophthalmology; 2005. Available at: www.aao.org/ppp Accessed 2010 March 4.

9. Netland PA, Landry T, Sullivan EK, et al. Travoprost compared with latanoprost and timolol in patients with open-angle glaucoma or ocular hypertension. Am J Ophthalmol. 2001;132(4):472-484.

10. Goldberg I, Cunha-Vaz J, Jakobsen JE, et al. Comparison of topical travoprost eye drops given once daily and timolol $0.5 \%$ given twice daily in patients with open-angle glaucoma or ocular hypertension. J Glaucoma. 2001;10(5):414-422.

11. Franks WA, Renard JP, Cunliffe IA, et al. A 6-week, double-masked, parallel-group study of the efficacy and safety of travoprost $0.004 \%$ compared with latanoprost $0: 005 \% /$ timolol $0.5 \%$ in patients with primary open-angle glaucoma or ocular hypertension. Clin Ther. 2006;28(3):332-339.

12. Sharif NA, Crider JY, Husain S, et al. Human ciliary muscle cell responses to FP-class prostaglandin analogs: Phosphoinositide hydrolysis, intracellular $\mathrm{Ca}^{2+}$ mobilization and MAP kinase activation. J Ocul Pharmacol Ther. 2003;19(5):437-455.
13. Sharif NA, Kelly CR, Crider JY, et al. Ocular hypotensive FP prostaglandin (PG) analogs: $\mathrm{PG}$ receptor subtype binding affinities and selectivities, and agonist potencies at FP and other PG receptors in cultured cells. J Ocul Pharmacol Ther. 2003;19(6):501-515.

14. Hellberg MR, Sallee VL, McLaughlin MA, et al. Preclinical efficacy of travoprost, a potent and selective FP prostaglandin receptor agonist. J Ocul Pharmacol Ther. 2001;17(5):421-432.

15. Schachtschabel U, Lindsey JD, Weinreb RN. The mechanism of action of prostaglandins on uveoscleral outflow. Curr Opin Ophthalmol. 2000;11(2):112-115.

16. Denis P, Covert D, Realini A. Travoprost in the management of open-angle glaucoma and ocular hypertension. Clin Ophthalmol. 2007;1(1)11-24.

17. DuBiner HB, Sircy MD, Landry T, et al. Comparison of the diurnal ocular hypotensive efficacy of travoprost and latanoprost over a 44-hour period in patients with elevated intraocular pressure. Clin Ther. 2004;26(1):84-91.

18. Gordon MO, Beiser JA, Brandt JD, et al. The Ocular Hypertension Treatment Study: A randomized trial determines that topical ocular hypotensive medication delays or prevents the onset of primary openangle glaucoma. Arch Ophthalmol. 2002;120(6):701-713.

19. Figueiredo CRL, Suzuki Jr, Ribeiro BB, et al. The effect of bimatoprost, latanoprost, travoprost and unoprostone on intraocular pressure and ocular blood flow. Rev Bras Oftalmol. 2002;61(12):863-869.

20. Parrish RK, Palmberg P, Sheu WP. A comparison of latanoprost, bimatoprost, and travoprost in patients with elevated intraocular pressure: A 12-week, randomized, masked-evaluator multicenter study. Am J Ophthalmol. 2003;135(5):688-703.

21. Cantor LB, Hoop J, Morgan L, et al. Intraocular pressure-lowering efficacy of bimatoprost $0.03 \%$ and travoprost $0.004 \%$ in patients with glaucoma or ocular hypertension. Br J Ophthalmol. 2006;90(11):1370-1373.

22. Suzuki ER Jr, Franklin LM, da Silva LJ, et al. Comparison of the efficacy and safety of travoprost with a fixed-combination of dorzolamide and timolol in patients with open-angle glaucoma or ocular hypertension. Curr Med Res Opin. 2006;22(9):1799-1805.

23. Asrani S, Zeimer R, Wilensky J, et al. Large diurnal fluctuations in intraocular pressure are an independent risk factor in patients with glaucoma. J Glaucoma. 2000;9(2):134-142.

24. Nouri-Mahdavi K, Hoffman D, Coleman AL, et al. Predictive factors for glaucomatous visual field progression in the Advanced Glaucoma Intervention Study. Ophthalmology. 2004;111(9):1627-1635.

25. Orzalesi N, Rossetti L, Bottoli A, et al. Comparison of the effects of latanoprost, travoprost, and bimatoprost on circadian intraocular pressure in patients with glaucoma or ocular hypertension. Ophthalmology. 2006;113(2):239-246.

26. Garcia-Feijoo J, Martinez-de-la-Casa JM, Castillo A, et al. Circadian IOP-lowering efficacy of travoprost $0.004 \%$ ophthalmic solution compared to latanoprost $0.005 \%$. Curr Med Res Opin. 2006;22(9):1689-1697.

27. Schuman JS, Katz GJ, Lewis RA, et al. Efficacy and safety of a fixed combination of travoprost $0.004 \% /$ timolol $0.5 \%$ ophthalmic solution once daily for open-angle glaucoma or ocular hypertension. Am J Ophthalmol. 2005;140(2):242-250.

28. Hughes BA, Bacharach J, Craven ER, et al. A three-month, multicenter, double-masked study of the safety and efficacy of travoprost $0.004 \%$ / timolol $0.5 \%$ ophthalmic solution compared to travoprost $0.004 \%$ ophthalmic solution and timolol $0.5 \%$ dosed concomitantly in subjects with open angle glaucoma or ocular hypertension. J Glaucoma. 2005;14(5):392-399.

29. Ong LB, Liza-Sharmini AT, Chieng LL, et al. The efficacy of timolol in gel-forming solution after morning or evening dosing in Asian glaucomatous patients. J Ocul Pharmacol Ther. 2005;21(5):388-394.

30. Reiss GR, Lee DA, Topper JE, et al. Aqueous humor flow during sleep. Invest Ophthalmol Vis Sci. 1984;25(6):776-778.

31. Denis P, Andrew R, Wells D, et al. A comparison of morning and evening instillation of a combination travoprost $0.004 \% /$ timolol $0.5 \%$ ophthalmic solution. Eur J Ophthalmol. 2006;16(3):407-415. 
32. Pfeiffer N, Scherzer ML, Maier H, et al. Safety and efficacy of changing to the travoprost/timolol maleate fixed combination (DuoTrav) from prior mono- or adjunctive therapy. Clin Ophthalmol. 2010;4: 459-466.

33. Feldman RM, Tanna AP, Gross RL, et al; Additivity Study Group. Comparison of the ocular hypotensive efficacy of adjunctive brimonidine $0.15 \%$ or brinzolamide $1 \%$ in combination with travoprost $0.004 \%$. Ophthalmology. 2007;114(7):1248-1254.

34. O'Connor DJ, Martone JF, Mead A. Additive intraocular pressure lowering effect of various medications with latanoprost. Am J Ophthalmol. 2002;133(6):836-837.

35. Konstas AG, Karabatsas CH, Lallos N, et al. 24-hour intraocular pressures with brimonidine purite versus dorzolamide added to latanoprost in primary open-angle glaucoma subjects. Ophthalmology. 2005;112(4):603-608.

36. Reis R, Queiroz CF, Santos LC, Avila MP, Magacho L. A randomized, investigator-masked, 4-week study comparing timolol maleate $0.5 \%$, brinzolamide $1 \%$, and brimonidine tartrate $0.2 \%$ as adjunctive therapies to travoprost $0.004 \%$ in adults with primary open-angle glaucoma or ocular hypertension. Clin Ther. 2006;28(4):552-559.

37. Covert D, Robin AL. Adjunctive glaucoma therapy use associated with travoprost, bimatoprost, and latanoprost. Curr Med Res Opin. 2006;22(5):971-976.

38. Alm A, Schoenfelder J, McDermott J. A 5-year, multicenter, open label, safety study of adjunctive latanoprost therapy for glaucoma. Arch Ophthalmol. 2004;122(7):957-965.
39. Mirza SK, Johnson SM. Efficacy and patient tolerability of travoprost BAK-free solution in patients with open-angle glaucoma and ocular hypertension. Clin Ophthalmol. 2010;4:877-888.

40. Yamazaki S, Nanno M, Kimura T, Suzumura H, Yoshikawa K. Effects of switching to SofZia-preserved travoprost in patients who presented with superficial punctate keratopathy while under treatment with latanoprost. Jpn J Ophthalmol. 2010;54(1):7-14.

41. Cellini M, Caramazza R, Bonsanto D, et al. Prostaglandin analogs and blood-aqueous barrier integrity: A flare cell meter study. Ophthalmologica. 2004;218(5):312-317.

42. Arcieri ES, Santana A, Rocha FN, et al. Blood-aqueous barrier changes after the use of prostaglandin analogues in patients with pseudophakia and aphakia: A 6-month randomized trial. Arch Ophthalmol. 2005;123(2):186-192.

43. Ayyala RS, Cruz DA, Margo CE, et al. Cystoid macular edema associated with latanoprost in aphakic and pseudophakic eyes. Am J Ophthalmol. 1998;126(4):602-604.

44. Carrillo MM, Nicolela MT. Cystoid macular edema in a low-risk patient after switching from latanoprost to bimatoprost. Am J Ophthalmol. 2004;137(5):966-968.

45. Watanabe K, Hayasaka S, Hayasaka Y, et al. Cystoid macular edema associated with latanoprost use in a pseudophakic eye with a history of surgical complications. Jpn J Ophthalmol. 2003;47(1):110-112.

46. Tokunaga T, Kashiwagi K, Saito J, et al. A case of cystoid macular edema associated with latanoprost ophthalmic solution. Jpn J Ophthalmol. 2002;46(6):656-659.
Clinical Ophthalmology

\section{Publish your work in this journal}

Clinical Ophthalmology is an international, peer-reviewed journal covering all subspecialties within ophthalmology. Key topics include: Optometry; Visual science; Pharmacology and drug therapy in eye diseases; Basic Sciences; Primary and Secondary eye care; Patient Safety and Quality of Care Improvements. This journal is indexed on

Submit your manuscript here: http://www.dovepress.com/clinical-ophthalmology-journal

\section{Dovepress}

PubMed Central and CAS, and is the official journal of The Society of Clinical Ophthalmology (SCO). The manuscript management system is completely online and includes a very quick and fair peer-review system, which is all easy to use. Visit http://www.dovepress.com/ testimonials.php to read real quotes from published authors. 